\title{
Customer-Centric Organizational Culture of the University as a Factor of Efficient Social and Economic Development of the Region
}

\author{
Irina Shavyrina ${ }^{1 *}$, Inna Demenenko ${ }^{1}$, and Elena Kravchenko ${ }^{2}$ \\ ${ }^{1}$ Belgorod State Technological University named after V. G. Shukhov, Department of Sociology and Management, 308012, \\ Belgorod, Russia \\ ${ }^{3}$ Belgorod University of Cooperation, Economics and Law, Department of Marketing and Management, 308023, Belgorod, \\ Russia
}

\begin{abstract}
The paper considers the customer-centric approach to the organizational culture of the university. The study of formation and development of customer-centric organizational culture of higher educational institutions as a factor of efficient social and economic development of the region is based on the designed diagnostic model of customer-centric organizational culture of the university encompassing the following group of components: degree of formation of customercentric organizational culture at the university at various levels (ideological, regulatory, customerfacing); degree of students' satisfaction; degree of students' involvement in the organizational culture of the university and outcomes of the influence of the university organizational culture on them. The customer-centric approach is considered, first as the focus of each member (employee) on the consumer (assessment of the orientation level of each participant), second, assessment of the consumer satisfaction level, allows estimating the level of consumer-focus in general without an attempt to identify orientation of every individual participant. The process of creating the additional value covers all above-mentioned levels and cannot be created with only one without taking the other into account. Therefore, it is critical to collect and make the best use of information and both real and potential consumer services.
\end{abstract}

\section{Introduction}

Modern functioning mechanism of the university is only possible through radical reorganization of the existing management system taking into account the accumulated positive experience and attraction of new organizational elements improving harmony and adaptability to external and internal changes. Customer-centric approach to university management, which depends on historically developed ratio of centralization and decentralization, readiness of top management and structural divisions to change the relations within the university, general culture of the organization, innovative and creative potential of employees, plays an important role.

Authors believe that the formation of customercentric organizational culture of the university as a factor of efficient social and economic development of the region is caused by the following:

first, the increasing role of a sociocultural aspect in training competitive staff for Russian enterprises;

second, the strengthening of integration between educational and industrial institutions requiring the development of new algorithms of mutually beneficial cooperation; third, the need to increase the customer focus of educational institutions through new organizational and technological mechanisms of formation and development of organizational culture providing reasonable balance of interests of all stakeholders of the educational process [1].

\section{Literature review}

The ambiguity of organizational culture predetermined some approaches to understanding this phenomenon in research practice. Among foreign scientists who made the first attempt of understand methodological fundamentals of organizational culture was $\mathrm{K}$. Jesper who considered the organizational culture as the "corporate religion" covering the belief of the organization in itself and its dreams [2]. K. Cameron and R. Quinn proposed the complex typology of organizational culture that includes two groups of criteria: main indicators of company performance and focus of its activity [3]. According to F. Harris and R. Moeran's approach, the organizational culture is determined not by the simple sum of expectations and the real situation of every characteristic, but by how they

* Corresponding author: shavyrina_77@mail.ru 
are interconnected and how do they form profiles of certain cultures [4]. S.P. Robbins defines the organizational culture from the perspective of such characteristics as personal initiative, degree of risk, coherence and orientation of actions, administrative support, control, identity, remuneration system, proneness to conflicts and communication patterns [5]. E. Schein believes that the culture of the organization is a pattern (scheme, model) of basic collective ideas identified by a group when solving problems of adaptation to changes of the external environment and internal integration [6]. According to G. Hofstede, the organizational culture is, first of all, defined by values shared by the majority of company employees [7].

Various aspects of formation and development of the university organizational culture are described by $\mathrm{T}$. Antopolskaya [8]. The author believes that by influencing the development of every subject the organizational culture creates conditions for their activity as unique "identities" united in a single space and demonstrating the feeling of "us", which further promotes the involvement phenomenon. Involvement is represented by mutual acceptance, mutual trust, mutual respect, empathy for the success of a common cause.

$\mathrm{K}$. Anderson and C. Kerr consider the issues of customer-centric management as a factor to enhance the competitiveness of modern organizations [9]. The general specific features of a sociocultural component within institutions of higher professional education were mainly driven by the ideas of D. Peppers and M. Rogers, which revealed problems of relationship between modern higher educational institutions and internal and external clients [10]. According to A.A. Chubatyuk, the customer-centric approach implies active introduction of marketing philosophy, marketing concept and tools into a management system of any business [11]. A. B. Zigalenko's organizational culture of the university is presented as the changing organism based on historically developed core values of the organization, which, in turn, form the basis for a specific impact on external factors [12].

In many respects successful adaptation of university graduates depends on the corporate culture of those organizational structures where they come to upon leaving the university. V.K. Borisov and I.V. Groshev analyzed various aspects of formation and development of corporate culture of modern organizations, including the factor of successful adaptation of graduates to professional activity [13]. When considering the organizational culture as a complex and multifunctioned system T.O. Solomanidina defines priority and importance of separate functions as the changing indicator depending on the type of organizational culture, its objectives, stage of development, influence of external environment. However, at the same time, according to the author of this theory, the combination of functions of organizational culture remains invariable and includes informative, value-forming, communicative, regulatory, motivating, innovative, and stabilizing functions [14].

The analysis of domestic and foreign sources on the matter allows concluding that at present humanities are characterized by a bulk of theoretical and empirical material regarding the issue of organizational culture influence on the efficiency of specialists' training at universities. At the same time, it is possible to draw a conclusion on the existence of considerable lack of study aimed at development of technologies and mechanisms to increase the customer-centric organizational culture of modern educational institutions.

\section{Instrument}

The study of clients involvement into the university organizational culture, level of satisfaction of internal and external clients with its organizational culture and effectiveness of its impact on internal and external clients was based on questionnaires among the university students $(\mathrm{N}=801)$. The field study took place in September-November, 2016. The sampling population made 801 respondents. The sampling population represented the following social and demographic groups. By gender: men $-45.02 \%$, women $-54.98 \%$. Depending on the university profile the number of respondents was distributed as follows: humanities $61.86 \%$, technical universities $-38.14 \%$. Within the status position of the university: state universities $71.48 \%$, private schools $-28.52 \%$. According to the study, the year of study turned to be one of the critical parameters. Thus, the sampling population of the firstyear students made $29.55 \%$, the second or third $35.74 \%$, and the fourth-year $-34.71 \%$.

\section{Findings and discussion}

The customer-centric organizational culture of the university is understood as the system of values, behavioral norms, traditions, rituals and symbols used to achieve the highest performance in the educational process [15]. The authors believe that the customercentric organizational culture of the university by no means diminishes the primary role of the university as a social institute on the production of culture, intellectual potential, civic consciousness and spirituality, but rather supplements it. The quality of education, professionalism of teachers, innovative component, etc. have always been and will be those criteria, according to which the university is valued. But, nevertheless, the emergence and development of the education market, formation of effective educational system set some strategic tasks to educational institutions, and universities, in particular, caused by the need of university adaptation to specific market conditions, which defines the shift in the development focus of a higher educational institution.

The authors developed the diagnostic model of customer-centric organizational culture of the university, including the below mentioned group of components to study the level of formation and development of customer-centric organizational culture of the university as a factor of efficient social and economic development of the region: 
1) degree of formation of customer-centric organizational culture of the university at various levels (ideological, regulatory, customer-facing);

2) degree of students' satisfaction within the university environment;

3) degree of students' involvement into the organizational culture of the university and efficiency of its influence.

Each component was focused on parameters studying the customer-centric organizational culture of the university.

The degree of customer-centric organizational culture at the university at the ideological level represents the development and deployment of the development strategy for customer-centric organizational culture including philosophy, mission and ideology of the university development. According to the study, when choosing the university the respondents highlight the availability of specialty under interest $(64.60 \%)$, quality of education $(49.83 \%)$ and the status value of the university as such (25.77\%). Parents advice (19.24\%), certain number of friends, acquaintances and relatives entering the same university $(17.18 \%)$ and affordable tuition fee $(14.78 \%)$ were also critical for respondents. Thus, certain determinants defining the choice of the university - quality, status value, and acceptability are formed.

One of the study parameters was the university development strategy. Nearly a half of respondents $46.74 \%$ - consider that the university development strategy is aimed for high-quality education. This is followed by favorable study conditions $(43.30 \%)$. Certainly, it is a rather positive aspect characterizing not only students understanding of the university strategic development but also its real focus. It characterizes universities of the Belgorod region as organizations dynamically developing within modern conditions, in compliance with federal requirements and standards, as well as positioning themselves as customer-centric social organizations. Besides, $(39.86 \%)$ respondents noted that the university development strategy involves the attraction of a bigger number of students and thus the maximum profit on services provided $(24.74 \%)$. This defines the real position of the university as the organization providing educational services in the conditions of existing commercialization of higher education.

At the regulatory level, the degree of formation of the university customer-centric organizational culture represents norms, created values, behavioral patterns, staff motivation. In this case, not only the value orientation of employees, but also general organizational commitment to create such values is important for the consumer. It is critical here to understand how this process is implemented in practice and is reflected in the activity of employees.

Nearly a half of respondents (49.14\%) think that traditions and customs, assigned norms and rules of conduct, as well as values form an integral part of the university and are shared by all participants of the educational process. Nevertheless, $24.40 \%$ of respondents mark them as rather declared than real, and
$20.27 \%$ - specify their existence, but at the same time the fact that they are not shared by all participants of the educational process. $5.15 \%$ of respondents categorically state their absence. The authors believe that this distribution of responses demonstrates, on the one hand, that such elements of the university organizational culture as traditions, customs, assigned norms and rules of conduct, values are typical and shared in the university, which indicates customer-centric approach of the university in relation to its "product", but, on the other hand, they are declarative.

The level of formation of customer-centric organizational culture of the university at the regulatory level and at the level of students' satisfaction was considered through the estimation of personal/professional qualities of teachers. Proceeding from obtained data, it is possible to build a certain hierarchy of personal and professional qualities of teachers: professionalism; personal qualities; communicative skills and competences; methods and practices of working with students; motivation and individual approach. Moreover, the study of commitment to the university demonstrates rather low level of teaching staff loyalty and automatic working mode caused by excessive overload and fear to lose it.

The level of formation of customer-centric organizational culture at the customer-facing level represents cross-boundary collaboration (communication, image, branding). This was measured by the way the work is organized at the university. More than a half of respondents mark the sense of belonging among all structural divisions (57.39\%). In this case, the year of study represents the dependent variable, which defines the obtained responses. If $75.58 \%$ of first-year students indicate smooth and consolidated work of all structural divisions, then only $40.59 \%$ of undergraduates think the same. Besides, the year of study also influences the isolated work of all structural divisions. Thus, the integration of students into the students' environment of the university and its attribution leads to qualitative assessment of work organization at the university on the basis of interaction with structural divisions.

Such parameter as the university profile (orientation) towards internal and external clients was measured by means of priority direction of orientation. A half of respondents $(51.20 \%)$ believe that the university administration plays a key role, while a student as a key figure only takes the second position (22.68\%). At the same time, $13.75 \%$ of respondents found it difficult to answer the question, which in total makes 110 people. Another interesting fact is that the teacher as the key player is only considered by $12.37 \%$ of respondents, while, the university staff is never assigned this role in general. Moreover, the results of the study showed that at the stage of admission, the university is focused on entrants, while during the education it is shifted towards university teachers and staff and only then towards students as a product of the educational process. This approach also defines the degree of the university's focus on major customers of the educational environment (entrants, students, teachers and staff, parents). 
The degree of students' satisfaction with the university environment showed that respondents are more or less satisfied with the university infrastructure and services (sports facilities, sites, swimming pools (4.40), development, comfort and conditions of study rooms (4.35), library and provided services (4.28). The following six positions estimated by respondents within the radius of 4 points represent valuable, esthetic and common cultural norms $(4.22 ; 4.10 ; 4.02)$ and professionalism of teachers along with the quality of educational services (4.21 and 4.03). The degree of students' satisfaction with the university environment was measured by indicators of dissatisfaction when interacting with teachers. The main components of students' dissatisfaction are expressed in excessive overload of teachers $(46.05 \%)$ and low communicative environment between students and teachers $(25.09 \%)$, isolation of teachers from students, lack of positive atmosphere $(23.02 \%)$, and, as a result, problems in development of customer-centric organizational culture of the university.

The degree of students' involvement into the university organizational culture and the influence of such organizational culture on them was measured by such parameter as individualization of consumers of educational services. Despite rather positive evaluation, a half of respondents indicated individualization of consumers of educational services at the admission stage, nevertheless, the cumulative percent of respondents at a loss and with negative answers also makes nearly a half of respondents $(45.71 \%)$. Besides, more than a half of respondents $-56.35 \%$ indicate the frequency of studying the degree of students' satisfaction with the educational process at the university. Nevertheless, the others $-27.84 \%$ - indicate either the random nature of such surveys (once during study) or lack of any monitoring at all (15.81\%).

The majority of respondents $-59.11 \%$ - consider that cooperation of university administration, including teachers, with students is aimed to maintain students' cohort. Rejection of a student as a vector of cooperation of university administration, including teachers, with students is only noted by $2.41 \%$ of respondents. Nevertheless, $38.49 \%$ of respondents indicate the neutral attitude towards students, which, in turn, means indifference from both administration and teachers. Such position shows that students do not consider themselves as a key customer of the university, towards which all areas of work necessary for self-development, are directed. It also demonstrates a certain isolation of students from other actors of the educational process.

The study of the degree of students' involvement into the university organizational culture and its influence was measured through differentiation of consumers of educational services. Thus, a half of respondents $(50.52 \%)$ note the creation of groups according to their interests, academic performance, further research activity. Another half of respondents were either at a loss $(35.74 \%)$ or indicated lack of that indicator $-13.75 \%$. These data, on the one hand, show a degree extent of students' differentiation, their involvement in research and existence of certain selection processes. However, at the same time, this characterizes students' involvement into the university organizational culture to a lesser extent and highlights weak connection between actors of the university cooperation.

The readiness to make a positive recommendation of the university $(46.71 \%)$ allows drawing a conclusion on the general satisfaction of clients (students) with the chosen university, and, therefore, on the increasing orientation towards the client (customer focus) in the conditions of heightened competition on the education market, as well as social and economic development of the region.

The main and strongly-pronounced problem in the study of customer-centric organizational culture at the university is the lack of developed links between external clients (employers) and educational institutions. This tendency is expressed in the increase of students' dissatisfaction with various areas of the university according to the study profile. At the graduation year, the student, being the "product" of the educational process, is ready to broadcast the gained knowledge, abilities, and skills in professional activity demonstrating high level of competence. However, facing the employment issue, students feel disappointed and, as a result, partially lose knowledge gained at the university. For this reason, the most important activity of the university shall be clear policy of partnership relations within the "university-employer" system ensuring continuity between students' community and university graduates.

The implementation of this approach is only possible at continuous monitoring of the loyalty level of potential clients, level of consumer satisfaction with services, consumer preferences and their expectations through market participants' feedback. Such system of partnership relations will ensure high level of customer focus of the university on the regional market of educational services and will create fundamentals for efficient social and economic development of the region.

\section{Conclusion}

Thus, the study of customer-centric organizational culture of the university as a factor of efficient social and economic development of the region provides for the following conclusions:

1) the existing organizational culture of universities does not reflect the customer-centric approach according to some indicators. Thus, within the existing organizational culture the following components of customer focus - product quality (full satisfaction); personnel; services and processes, as well as rules and standards, relations, are not revealed;

2 ) at present, the customer-centric approach is rather declarative than real;

3) the transformation of an organizational culture to a customer-centric structure requires encouragement of positive attitude towards clients within the organization; change of values and norms, creation of customer-centric standards and continuous monitoring of requirements of both internal and external clients through qualitative and 
quantitative study; change of a quality management system (each process shall be focused on the consumer); feedback, monitoring of competitors' products.

The formation and development of customer-centric organizational culture of the university is bound to the need of creating an additional value - focus on a client, a consumer of services. In this case, the customer focus of the university is considered, first of all, as the orientation of each member (employee) on the consumer (assessment of the orientation level of every participant), secondly, as the assessment of the level of consumer satisfaction with services, which allows estimating the level of orientation towards the consumer in general without an attempt to identify the orientation of each participant. The creation of the additional value is applicable to all above-mentioned levels and cannot be created at one level without the other. Therefore, it is critical to collect and make the best use of information and both real and potential consumer services.

\section{References}

1. Z.N. Avilova, I.A. Gulei, I.V. Shavyrina, Mediterranean Journal of Social Sciences 6(3), 207216 (2015)

2. B. Jesper Sorensen, Note on Organization Culture, Stanford (CA: Stanford Graduate School of Business, 2009)

3. K.S. Cameron, R.E. Quinn, Diagnosing and Changing Organizational Culture (AddissonWesley Publishing Co, 1999)

4. S.P. Robbins, Organizational Theory: Structure, Design and Application (Englewood Cliffs, NJ, 1987)

5. P.R. Harris, R.T. Moran, Managing cultural differences (N.Y, 1991)

6. E. Schein, Organizational Culture and Leadership (San-Francisco, 1985.)

7. G.Hofstede, Culture's consequences (Beverly Hills, 1980)

8. T. Antopolskaya, Alma mater: Bulletin of the higher school 7, 3-9 (2005)

9. K. Anderson, C. Kerr, Customer Relationship Management (McGraw-Hill Educatin, London, 2001)

10. D. Peppers, M. Rogers, Managing Customer Relationship: A strategic Framework (2011)

11. A.A. Chubatyuk, Theory and methodology of customer-centric business (SPb., 2011)

12. A.B. Zigalenko, Methodical fundamental of formation and development of organizational culture in the system of university entrepreneurship, (diss. ... cand. of ecocnomic, Volgograd, 2008)

13. I.V. Groshev, V.M. Yuryev, Management of organizational culture (M., 2010.

14. T.O. Solomanidina, Organizational culture of the company (M., 2007)
15. I.A. Gulei, O.A. Smolenskaya, I.V. Shavyrina, V.A. Shapovalova, Journal of Advanced Research in Law and Economics 6(3), 551-559 (2015) 